\title{
Circulating microvesicles and exosomes in small cell lung cancer by quantitative proteomics
}

\author{
Shona Pedersen ${ }^{1 *} \oplus \mathbb{D}$, Katrine Papendick Jensen ${ }^{2,4 \dagger}$, Bent Honoré ${ }^{2,3}$, Søren Risom Kristensen ${ }^{2,4}$, \\ Camilla Holm Pedersen ${ }^{5}$, Weronika Maria Szejniuk ${ }^{2,6}$, Raluca Georgiana Maltesen ${ }^{7}$ and Ursula Falkmer ${ }^{2,6}$
}

\begin{abstract}
Background: Early detection of small cell lung cancer (SCLC) crucially demands highly reliable markers. Growing evidence suggests that extracellular vesicles carry tumor cell-specific cargo suitable as protein markers in cancer. Quantitative proteomic profiling of circulating microvesicles and exosomes can be a high-throughput platform for discovery of novel molecular insights and putative markers. Hence, this study aimed to investigate proteome dynamics of plasma-derived microvesicles and exosomes in newly diagnosed SCLC patients to improve early detection.
\end{abstract}

Methods: Plasma-derived microvesicles and exosomes from 24 healthy controls and 24 SCLC patients were isolated from plasma by either high-speed- or ultracentrifugation. Proteins derived from these extracellular vesicles were quantified using label-free mass spectrometry and statistical analysis was carried out aiming at identifying significantly altered protein expressions between SCLC patients and healthy controls. Furthermore, significantly expressed proteins were subjected to functional enrichment analysis to identify biological pathways implicated in SCLC pathogenesis.

Results: Based on fold change $(F C) \geq 2$ or $\leq 0.5$ and $A U C \geq 0.70(p<0.05)$, we identified 10 common and 16 and 17 unique proteins for microvesicles and exosomes, respectively. Among these proteins, we found dysregulation of coagulation factor XIII A ( $\left.\log _{2} \mathrm{FC}=-1.1, p=0.0003, \mathrm{AUC}=0.82,95 \% \mathrm{Cl}: 0.69-0.96\right)$ and complement factor H-related protein $4\left(\log _{2} \mathrm{FC}=1.2, p=0.0005, \mathrm{AUC}=0.82,95 \% \mathrm{Cl} ; 0.67-0.97\right)$ in SCLC patients compared to healthy individuals. Our data may indicate a novel tumor-suppressing role of blood coagulation and involvement of complement activation in SCLC pathogenesis.

Conclusions: In comparing SCLC patients and healthy individuals, several differentially expressed proteins were identified. This is the first study showing that circulating extracellular vesicles may encompass specific proteins with potential diagnostic attributes for SCLC, thereby opening new opportunities as novel non-invasive markers.

Keywords: Small cell lung cancer, Proteomics, Tumor-derived exosomes, Tumor-derived microvesicles, Potential diagnostic markers

*Correspondence: spedersen@qu.edu.qa

†Shona Pedersen and Katrine Papendick Jensen contributed equally to this work

${ }^{1}$ Department of Basic Medical Sciences, College of Medicine, QU Health, Qatar University, 2713 Doha, Qatar

Full list of author information is available at the end of the article

\section{Background}

Lung cancer is the main cause of cancer-related deaths, and the second and third most prevalent cancer in Europe among men and women, respectively [1]. The main histopathological subtypes of lung cancer are small cell lung cancer (SCLC) and non-small cell lung cancer (NSCLC). SCLC is a neuroendocrine carcinoma original author(s) and the source, provide a link to the Creative Commons licence, and indicate if changes were made. The images or other third party material in this article are included in the article's Creative Commons licence, unless indicated otherwise in a credit line to the material. If material is not included in the article's Creative Commons licence and your intended use is not permitted by statutory regulation or exceeds the permitted use, you will need to obtain permission directly from the copyright holder. To view a copy of this licence, visit http://creativecommons.org/licenses/by/4.0/. The Creative Commons Public Domain Dedication waiver (http://creativeco mmons.org/publicdomain/zero/1.0/) applies to the data made available in this article, unless otherwise stated in a credit line to the data. 
that accounts for $\sim 15 \%$ of lung cancers and is characterized by an aggressive progression to early metastases $[2,3]$. Currently, the diagnosis is based on computed tomography $(\mathrm{CT})$ scan and cytology obtained by fineneedle aspiration (FNA) biopsy from the suspected lesion. While CT scans has a high sensitivity and low specificity due to a high false-positive rate [4], FNA is associated with a risk of complications [5]. The poor prognosis of SCLC patients is partially a consequence of late diagnosis, since two-thirds of patients present at advanced tumor stage at the time of diagnosis [3]. Thus, to minimize delays in diagnosis and improve patient safety, better diagnostic procedures are warranted.

Throughout the years, research has been aimed at finding easily accessible, cost-effective and non-invasive biomarkers in lung cancer [6]. Two proteins, NSE and ProGRP, have been documented as suitable for discriminating between NSCLC and SCLC [7] and it has been suggested that a panel including these markers may improve diagnosis [8]. Despite rigorous investigations, the ideal diagnostic biomarker for SCLC has yet not propertied a place in the clinic.

The emerging field of extracellular vesicles (EVs) has unraveled a novel approach for investigating SCLC. They are secreted by virtually all cells, including cancer cells, and are present in several body fluids, making EVs applicable as non-invasive liquid biomarkers [9]. Broadly, EVs are divided into exosomes (small EVs) and microvesicles (MVs or large EVs), which are continuously released under physiological and pathological conditions. The vesicles are loaded with a specific cargo, including lipids, proteins, and genetic material originating from the parent cell. Thus, the content of EVs may to some extent resemble the molecular profiles of the originating cells [10]. Therefore, the use of EVs may provide a revolutionary tool for investigating SCLC in a clinical setting. Proteomic analysis with discovery-based mass spectrometry (MS) is a relatively new approach for discovering novel biomarker candidates in several cancers. Profiling of EV proteomes using this approach has led to identification of novel diagnostic biomarkers in cancers, including ovarian and prostate cancer $[11,12]$. Recent studies have identified exosomal biomarkers with diagnostic potential in NSCLC patients using MS [13, 14]. The current study seeks to explore the proteome dynamics of plasmaderived exosomes and MVs from SCLC patients for the identification of significantly expressed proteins that can add new insights into lung cancer biology and early diagnosis. This is the first study inaugurating the potential role of circulating MVs and exosomes in SCLC diagnosis using quantitative proteomics.

\section{Methods}

\section{Subject characteristics}

This observational prospective study included data and blood samples from patients with SCLC, diagnosed and treated with chemotherapy between March 2015 to September 2017 at the Department of Oncology, Aalborg University Hospital, Denmark. Inclusion criteria were: eligibility to receive chemotherapy consisting of platinum and a topoisomerase inhibitor, histopathologically and/or cytologically confirmed SCLC, measurable disease on CT scans, and blood samples eligible for MS analysis. Exclusion criteria were: prior systemic chemotherapy for lung cancer, concomitant anticoagulation treatment (except aspirin or clopidogrel), active or at high risk of overt bleeding of clinical importance, severe coagulopathy such as haemophilia, severe liver dysfunction with impaired coagulation, acute peptic ulcer, intracranial haemorrhage or surgery in the central nervous system within the last 3 months, treatment with any other investigational agent, and participation in other clinical trials. The clinical data, administration of medications, treatment details, and radiological evaluation were collected at time of diagnosis. Staging of SCLC was based on the 7th edition of the tumor, lymph node, metastasis (TNM) classification of lung cancer [15]. The study was approved by the North Denmark Region Committee on Health Research Ethics (N-20140055), reported to the Danish Data Protection Authority (2018-731-5589) and performed in accordance with the Declaration of Helsinki. All included participants provided written informed consent before enrolment in the study. In addition, age-and gendermatched healthy controls (HCs) from the blood bank at Aalborg University Hospital were used for comparison.

\section{Sample collection and preparation}

Blood samples were collected from $\mathrm{HCs}$ and from SCLC patients at the time of inclusion (henceforth referred to as SCLC patients) as well as prior to third cycle of chemotherapy (treated SCLC patients). Blood was drawn from the antecubital vein using a vacutainer blood collection device with a 21-gauge needle (Vacuette, Greiner Bio-One, Austria) and collected in $9 \mathrm{~mL} 0.105 \mathrm{M}(3.2 \%)$ trisodium citrate tubes (BD Vacutainer $\left.^{\circledR}, \mathrm{UK}\right)$. Platelet-poor plasma was prepared by double centrifugation at $2500 \times g$ for $15 \mathrm{~min}$ at room temperature. Plasma collection was stopped $1 \mathrm{~cm}$ above the buffy coat and pellet, respectively, after first and second centrifugation. Subsequently, the plasma isolates were snap-frozen in liquid nitrogen and stored at $-80{ }^{\circ} \mathrm{C}$ until further analysis. 


\section{$\mathrm{EV}$ isolation and preparation for MS analysis}

EV isolation was performed from $1 \mathrm{~mL}$ plasma with one centrifugation at $20,000 \times g$ for $30 \mathrm{~min}$ at $4{ }^{\circ} \mathrm{C}$ using an Avanti J-30i centrifuge with a J A-30.50 fixed-angle rotor with a k-factor 280 (Beckman Coulter, Brea, CA, USA). The supernatant from the initial spin of the $20 \mathrm{~K}$ pellet was used to prepare the $100 \mathrm{~K}$ pellet $(100,000 \times g$ for $1 \mathrm{~h}$ at $4{ }^{\circ} \mathrm{C}$ ). Succeeding the initial centrifugation step for each pellet preparation, the resultant EVs were washed in $1 \mathrm{~mL}$ phosphate-buffered saline filtered by a $0.22 \mu \mathrm{m}$ filter. The final enriched $20 \mathrm{~K}$ (microvesicles; large EVs) and $100 \mathrm{~K}$ (exosomes; small EVs) samples were resuspended in $20 \mu \mathrm{L}$ filtered phosphate-buffered saline prior to MS analysis. The samples were lysed and solubilized in $5 \%$ sodium dodecyl sulfate containing $50 \mathrm{mM}$ triethylammonium bicarbonate, $\mathrm{pH}$ 7.55. Alkylation and tryptic digestion were performed using S-TrapTM Micro Spin Columns (Protifi, NY, USA) essentially as previously described [16]. Proteins were cleaved using PierceTM Trypsin protease, MS Grade (Thermo Fisher Scientific, Waltham, MA, USA) and peptide concentrations were measured by fluorescence using an EnSpire microplate reader (Perkin Elmer, Waltham, MA, USA). Samples were resuspended in $0.1 \%$ formic acid and injected with an amount of $1 \mu \mathrm{g}$ in case of $20 \mathrm{~K}$ sample and $0.75 \mu \mathrm{g}$ in case of $100 \mathrm{~K}$ sample.

\section{Label-free quantitative nano liquid chromatography- tandem mass spectrometry analysis}

The peptides from 20 and $100 \mathrm{~K}$ preparations were analysed on a nano liquid chromatography-tandem mass spectrometry platform consisting of an Ultimate 3000 and an Orbitrap Fusion Tribrid instrument from (Thermo Scientific Instruments, MA, USA) as previously described [17]. Samples were run in technical duplicates. Due to technical difficulties, two HCs from the $20 \mathrm{~K}$ group and two SCLC samples from the $100 \mathrm{~K}$ group could not be analysed. All in all 284 raw files were generated, $14220 \mathrm{~K}$ raw files and $142100 \mathrm{~K}$ raw files. The mass spectrometry proteomics data have been deposited to the ProteomeXchange Consortium [18] via the PRIDE [19] partner repository with the dataset identifier PXD028944 for the $20 \mathrm{~K}$ data and PXD028885 for the $100 \mathrm{~K}$ data.

\section{Protein identification and quantification}

Protein identification and label-free quantification (LFQ) were performed in two different searches, using the EV raw files against the human database from Uniprot (downloaded 09/02/2020 for $20 \mathrm{~K}$ and 10/08/2019 for $100 \mathrm{~K}$ ) and using MaxQuant version 1.6.6.0 (Max Planck Institute of Biochemistry, Martinsried, Germany) for LFQ analysis [20]. The number of entries in the Uniprot
Homo sapiens databases were 42,427 (downloaded 10/08/2019) and 48,918 (downloaded 09/02/2020). Carbamidomethyl $(\mathrm{C})$ was used as fixed modification, and the false discovery rate for peptide-spectrum matches, protein, and site were each set at $1 \%$. The maximum number of missed cleavage sites was 2 . The mass tolerance for precursor ions was $20 \mathrm{ppm}$ for the first search and $4.5 \mathrm{ppm}$ for the main search. The mass tolerance for fragment ions was $0.5 \mathrm{Da}$. The minimum ratio count for LFQ was set to 1 . Tandem mass spectrometry was required for LFQ comparisons. For quantification of proteins, unique and razor peptides, unmodified and modified with oxidation (M) or acetyl (protein N-terminal) were used. The function match between runs was used, reverse sequences were used for decoy search, and contaminant sequences were included in the search. The analysis in MaxQuant included samples from HCs, SCLC patients, and treated SCLC patients, however, the treated samples are excluded in the statistical analyses.

\section{Statistical analysis}

LFQ values for identified proteins were filtered in Perseus version 1.6.10.50 (Max Planck Institute of Biochemistry, Martinsried, Germany) [20] by the exclusion of potential contaminants, reverse sequences, and proteins only identified by site. A minimum of 2 unique peptides was needed for successful identification. LFQ values were $\log _{2}$ transformed and the mean of technical replicates was used for further analysis. Data distributions were assessed through histograms. Proteins were required to have $70 \%$ valid values in at least one group. A Venn diagram (Venny 2.1) [21] was used to investigate proteins common and unique for each group and identified proteins were matched to the top 100 identified proteins from the EV databases Vesiclepedia [22] and ExoCarta [23] (both databases downloaded 03/12/2020).

Data were presented as mean and standard deviations (mean \pm SD). Trends in samples were assessed using unsupervised principal component analysis (PCA) on autoscaled data. Differentially expressed proteins were identified between healthy and diseased individuals using a Student's t-test. Proteins were considered statistically significantly expressed if $\mathrm{p}<0.05$ and $\log _{2}$ fold change (FC) $\geq 1$ or $\leq-1$ and were visualized through volcano plots. Comparisons of protein expressions were depicted using raw LFQ values. Significantly expressed proteins presented in Table S4 were subjected to enrichment analysis and annotated with significant gene ontology biological process (GOBP) terms using the functional annotation clustering analysis by The Database for Annotation, Visualization, and Integrated Discovery (DAVID) version $6.8[24,25]$. 


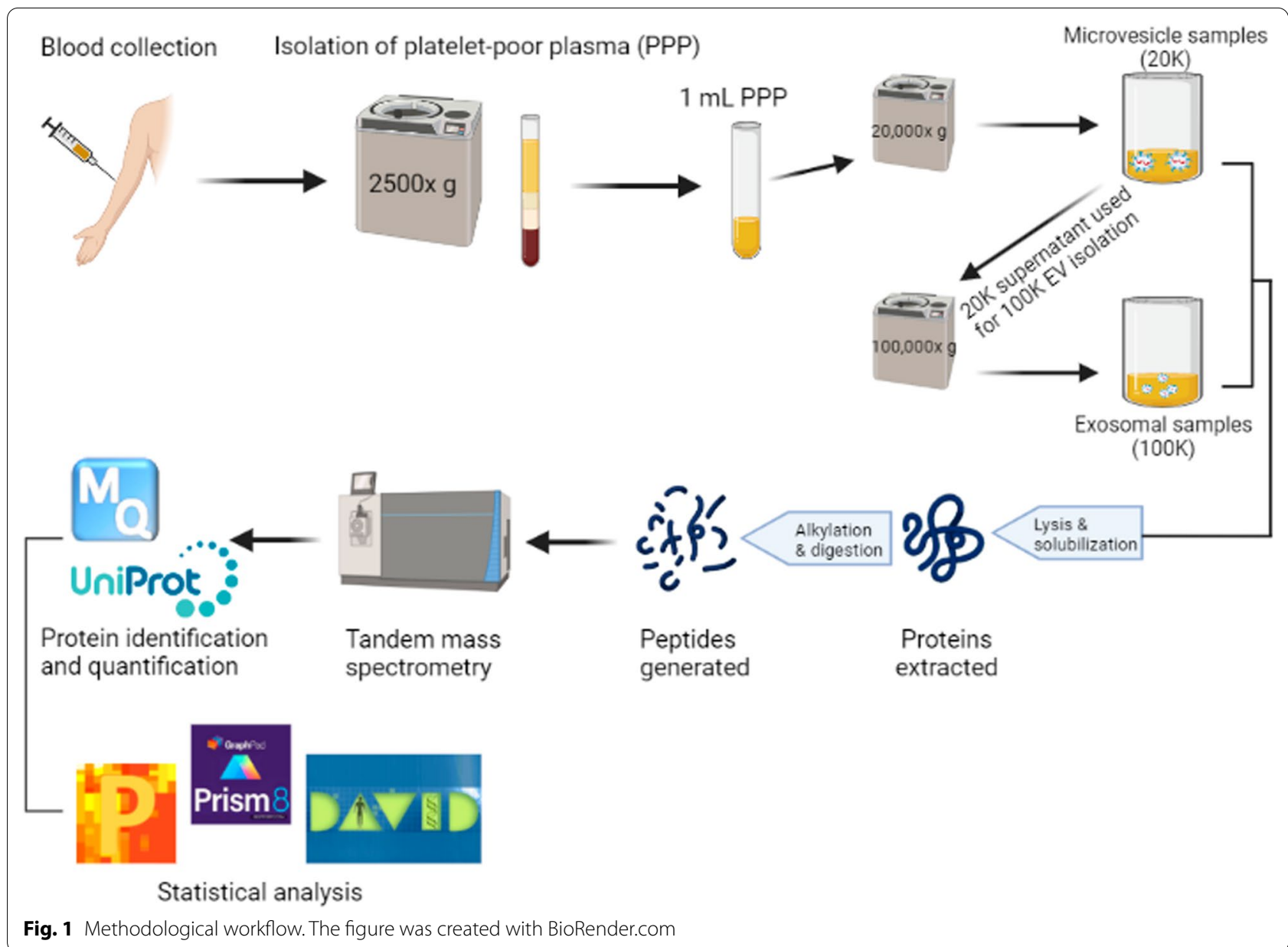

IBM SPSS Statistics 26 (SPSS, Chicago, IL, USA), MATLAB (R2017b, MathWorks, Natick, MA, 24 USA), and GraphPad Prism 8.4.3 (GraphPad Software, La Jolla, CA, USA) were used for statistical analysis. Figure 1 below provides an overview of the sample collection, EV isolation, MS characterization, and statistical analyses of the enriched vesicles.

\section{Results}

\section{Characteristics of study populations}

During the study period, 24 SCLC patients fulfilled the inclusion criteria and were enrolled in the study. A total of 24 matching individuals were enrolled as HCs. Gender and age distributions were balanced among individuals. More than $90 \%$ of the patients were diagnosed with advanced stage disease (Table 1 ).

\section{Proteomic analysis of circulating microvesicles} and exosomes

Plasma proteins of circulating MVs and exosomes were characterized and confirmed as previously described
Table 1 Demographics and patient characteristics of the study population

Study characteristics for SCLC patients and healthy controls

\begin{tabular}{lll}
\hline & SCLC patients & Healthy controls \\
\hline & $N=24$ & $N=24$ \\
Demographics & & $12 / 12$ \\
Sex (male/female, $N)$ & $12 / 12$ & $63.3 \pm 3$ \\
Mean age ( \pm SD) & $67 \pm 7$ & \\
Patient characteristics & & \\
TNM stage, N (\%) & \\
IIB & $1(4)$ & \\
IIIA & $6(25)$ & \\
IIIB & $3(13)$ & \\
IV & $14(58)$ & \\
\hline SCLC small cell lung cancer, N number of patients, SD standard deviations
\end{tabular}

[26] and in accordance with the Minimal Information for Studies of Extracellular Vesicles (MISEV) criteria [27]. Due to analytical troubleshooting, only 23 of the 24 
SCLC samples could be used to investigate exosomes. In total, 314 proteins were identified in MVs and 233 proteins in exosomes. For MVs, 51 of the identified proteins accorded with the top $100 \mathrm{EV}$ proteins from either Vesiclepedia or ExoCarta; of these, 36 proteins corresponded to both databases (Fig. 2a; Additional file 2: Table S1). For the exosome samples, 18 proteins overlapped with the top $100 \mathrm{EV}$ identified proteins from both Vesiclepedia and ExoCarta (Fig. 2b; Additional file 2: Table S1).

Patterns in data were visualized using PCA (Fig. 2c, d). Interestingly, samples cluster according to the health state of each individual along the first and the second principal components ( $\mathrm{PC} 1, \mathrm{PC} 2)$, indicating significant differences in MV (Fig. 2c) and exosome (Fig. 2d) protein profiles among HCs and SCLC patients.

For the MV samples (20 K), 10 distinct protein clusters were identified (Fig. 2e) with characteristic profiles (Fig. 2f). For the exosome samples (100 K), 12 distinct protein clusters were identified (Fig. 2g) with characteristic profiles (Fig. 2h). Additional information related to the distribution of proteins within clusters is summarized in Additional file 3: Table S2. Volcano plots illustrating the magnitude changes in protein expression between SCLC patients and HCs for $20 \mathrm{~K}$ and $100 \mathrm{~K}$ samples

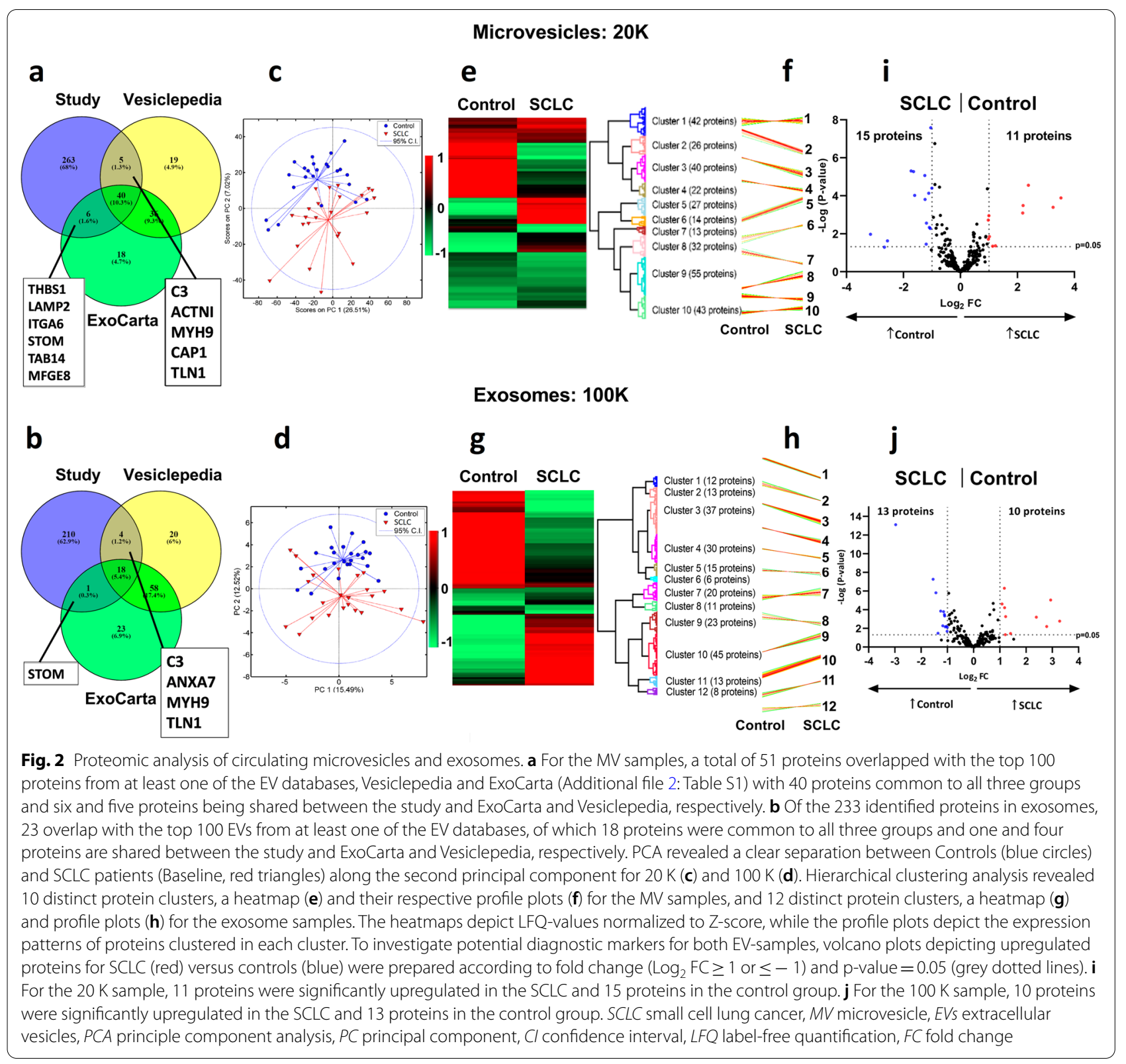


are depicted in Fig. 2i, j, respectively. Results from the functional enrichment analyses performed on the significantly up- and downregulated proteins are presented in Additional file 4: Table S3. For the $20 \mathrm{~K}$ samples, the proteins upregulated in SCLC patients are related to celland cell-matrix adhesion, integrin-mediated signaling, and extracellular matrix organization with an $E S \geq 3.18$ (Additional file 4: Table S3). For the $100 \mathrm{~K}$ samples, the upregulated proteins are related to among others, complement activation, cytolysis, lipoprotein-associated processes, and cholesterol transport with an $\mathrm{ES} \geq 4.56$ (Additional file 4: Table S3). No GOBP terms were found to be enriched for the proteins downregulated in the $20 \mathrm{~K}$ samples. However, a significant association was observed between these downregulated proteins and biological processes, such as platelet degranulation, blood coagulation, hydrogen peroxide catabolic process, extracellular matrix disassembly and -organization, cellular protein metabolic processes, and oxygen- and lipid transport (Additional file 4: Table S3). For the $100 \mathrm{~K}$ samples, the proteins downregulated in SCLC patients are related to among others complement activation, proteolysis, receptor-mediated endocytosis, phagocytosis, and immune response with an $E S \geq 4.46$ (Additional file 4: Table S3).

\section{Dynamics of microvesicle and exosomal proteins in SCLC diagnosis}

Protein expression analysis revealed 62 proteins being differentially expressed between SCLC patients and HCs for the MV samples, where 26 proteins were upregulated and 36 were downregulated in SCLC patients (Additional file 5: Table S4). For the exosome samples, 68 proteins were differentially expressed, whereof 29 proteins were upregulated and 39 were downregulated in SCLC patients compared to $\mathrm{HCs}(p<0.05)$ (Additional file 5: Table S4). A supplementary venn diagram was created to illustrate the proteins uniquely up- and downregulated for $20 \mathrm{~K}$ or $100 \mathrm{~K}$, respectively, and those that are commonly expressed (Additional file 1: Fig. S1). Significantly differentially expressed proteins between SCLC patients and HCs were selected for additional analysis $(p<0.05$ and $\log _{2} \mathrm{FC} \geq 1$ or $\leq-1$ ) (Additional file 5: Table S4). For MV samples, 11 proteins were upregulated and 15 proteins downregulated in SCLC patients compared to HCs and fulfilled the FC criteria (Fig. 2i). For the exosome samples, 10 proteins were upregulated and 13 proteins downregulated in SCLC compared to HCs and fulfilled the FC criteria (Fig. 2j). Table 2 presents the 10 proteins common between MVs and exosomes with $\log _{2} \mathrm{FC} \geq 1$ or $\leq-1$ in at least one of the vesicle types, the 16 proteins unique for MVs, and the 17 proteins unique for exosomes (data based on both on $p$-values $<0.05$ and $\log _{2} F C \geq 1$ or $\leq-1)$.
To assess the diagnostic capacity of the most significantly expressed proteins in the groups, receiver operating characteristics (ROC) analysis was conducted. Top 10 proteins (with $\mathrm{AUC} \geq 0.8$ ) for the $\mathrm{MV}(20 \mathrm{~K})$ and exosome $(100 \mathrm{~K})$ samples, respectively, are visualized in Fig. 3a, b, and additional information can be found in Additional file 6: Table S5.

In addition to the top 10 most distinct proteins among groups, a range of proteins which have previously been found in association with cancer also revealed acceptable sensitivity and specificity (Table 3 ).

\section{Discussion}

Small cell lung cancer is the most aggressive form of lung cancer with early metastasis resulting in poor prognosis. Therefore, it would be favourable to identify characteristic markers to improve the early detection of SCLC. We present results of a comprehensive untargeted quantitative MS-based proteomics analysis on plasma-derived MVs and exosomes from HCs and newly diagnosed SCLC patients, aiming at identifying easily accessible putative markers.

In our study, 233 exosomal and 314 MV-derived proteins were investigated for diagnostic potential in SCLC. We observed several tumor-derived MV and exosomal proteins capable of differentiating between SCLC patients and HCs with high efficacy (Fig. 3a, b; Table 3). Uniquely for the MV samples, the upregulated proteins were found to be related to cell adhesion, integrin-mediated signaling, and extracellular matrix organization, while the upregulated exosomal proteins are exclusively related to cytolysis, and lipid- and cholesterol remodelling. Moreover, for the MV samples, the downregulated proteins were found to be uniquely related to platelet degranulation, blood coagulation, hydrogen peroxide catabolic process, and oxygen- and bicarbonate transport, whereas the downregulated exosomal proteins are specifically related to receptor-mediated endocytosis, proteolysis, immune response, and phagocytosis (Additional file 4: Table S3). Interestingly, we found that complement activation and -regulation is associated with both the up- and downregulated exosomal proteins, indicating an important role of the complement cascade in SCLC pathogenesis (Additional file 4: Table S3). Despite these differences in the biological pathways associated with MV-derived and exosomal proteins, the proteome manifestation of MVs and exosomes for SCLC diagnosis appears to be partly comparable according to Fig. 3a, b; Additional file 4: Table S3). In the following, we attempt to syndicate markedly expressed proteins that are shared in SCLC, NSCLC, and other cancer types, and unraveling those that are novel for SCLC. 
Table 2 Significantly differentially expressed proteins for $20 \mathrm{~K}$ and $100 \mathrm{~K}$ comparing SCLC to the control group

\section{SCLC|control: common proteins in microvesicle ( $20 \mathrm{~K}$ ) and exosome (100 K) samples}

\begin{tabular}{|c|c|c|c|c|c|c|}
\hline \multirow[t]{2}{*}{ Uniprot ID } & \multirow[t]{2}{*}{ Gene name } & \multirow[t]{2}{*}{ Protein name } & \multicolumn{2}{|c|}{$\log _{2} F C$} & \multicolumn{2}{|l|}{$p$-value } \\
\hline & & & $20 \mathrm{~K}$ & $100 \mathrm{~K}$ & $20 \mathrm{~K}$ & $100 \mathrm{~K}$ \\
\hline P02741 & CRP & C-reactive protein & 3.5 & 1.2 & 0.0001 & 0.0016 \\
\hline P15144 & ANPEP & Aminopeptidase N & 3.2 & 2.4 & 0.0004 & 0.0006 \\
\hline PODJI8 & SAA1 & Serum amyloid A-1 protein & 2.4 & 2.9 & $<0.0001$ & $<0.0001$ \\
\hline P02763 & ORM1 & Alpha-1-acid glycoprotein 1 & 1.0 & 0.4 & 0.0011 & 0.0474 \\
\hline P02750 & LRG1 & Leucine-rich alpha-2-glycoprotein & 0.9 & 1.2 & 0.0140 & $<0.0001$ \\
\hline P00738 & $\mathrm{HP}$ & Haptoglobin & 0.9 & 1.2 & 0.0004 & $<0.0001$ \\
\hline P06396 & GSN & Gelsolin & -1.0 & -0.7 & $<0.0001$ & 0.0001 \\
\hline P69905 & HBA1 & Hemoglobin subunit alpha & -1.2 & -1.4 & 0.0002 & $<0.0001$ \\
\hline P06727 & APOA4 & Apolipoprotein A-IV & -1.1 & -0.6 & 0.0001 & 0.0109 \\
\hline P68871 & $\mathrm{HBB}$ & Hemoglobin subunit beta & -1.6 & -0.9 & $<0.0001$ & 0.0003 \\
\hline
\end{tabular}

SCLC|control: proteins detected only in the microvesicle samples ( $20 \mathrm{~K})$

\begin{tabular}{|c|c|c|c|c|}
\hline Uniprot ID & Gene name & Protein name & $\log _{2} F C$ & $p$-value \\
\hline P02786 & TFRC & Transferrin receptor protein 1 & 2.2 & 0.0003 \\
\hline Q08380 & LGALS3BP & Galectin-3-binding protein & 2.2 & 0.0008 \\
\hline P05164 & MPO & Myeloperoxidase & 1.2 & 0.0424 \\
\hline Q13418 & ILK & Integrin-linked protein kinase & 1.0 & 0.0140 \\
\hline P23229 & ITGA6 & Integrin alpha-6 & 1.0 & 0.0193 \\
\hline Q96PD5 & PGLYRP2 & $\mathrm{N}$-acetylmuramoyl-L-alanine amidase & -1.0 & $<0.0001$ \\
\hline 000391 & QSOX1 & Sulfhydryl oxidase 1 & -1.1 & 0.0052 \\
\hline P02724 & GYPA & Glycophorin-A & -1.1 & 0.0046 \\
\hline P00915 & CA1 & Carbonic anhydrase 1 & -1.2 & 0.0028 \\
\hline P32119 & PRDX2 & Peroxiredoxin-2 & -1.2 & 0.0351 \\
\hline Q15582 & TGFBI & $\begin{array}{l}\text { Transforming growth factor-beta-induced protein } \\
\text { ig-h3 }\end{array}$ & -1.2 & $<0.0001$ \\
\hline P02730 & SLC4A1 & Band 3 anion transport protein & -1.6 & 0.0001 \\
\hline P02042 & $\mathrm{HBD}$ & Hemoglobin subunit delta & -1.7 & $<0.0001$ \\
\hline P16157 & ANK1 & Ankyrin-1 & -2.6 & 0.0233 \\
\hline P11277 & SPTB & Spectrin beta chain erythrocytic & -2.7 & 0.0502 \\
\hline P02549 & SPTA1 & Spectrin alpha chain erythrocytic 1 & -3.2 & 0.0106 \\
\hline
\end{tabular}

SCLC|control: proteins detected only in the exosome samples (100 K)

\begin{tabular}{|c|c|c|c|c|}
\hline Uniprot ID & Gene name & Protein name & $\log _{2}$ FC & p-value \\
\hline PODJI8 & SAA2 & Serum amyloid A-1 protein & 3.3 & 0.0016 \\
\hline P02655 & APOC2 & Apolipoprotein C-II & 2.8 & 0.0062 \\
\hline P08519 & LPA & Apolipoprotein(a) & 1.4 & 0.0346 \\
\hline Q92496 & CFHR4 & Complement factor H-related protein 4 & 1.2 & 0.0005 \\
\hline P04114 & APOB & Apolipoprotein B & 1.1 & $<0.0001$ \\
\hline P00736 & $\mathrm{C} 1 \mathrm{R}$ & Complement $\mathrm{C} 1 \mathrm{r}$ subcomponent & -1.0 & 0.0077 \\
\hline Q06830 & PRDX1 & Peroxiredoxin-1 & -1.0 & 0.0203 \\
\hline P05160 & $\mathrm{F} 13 \mathrm{~B}$ & Coagulation factor XIII B chain & -1.0 & 0.0060 \\
\hline P48740 & MASP1 & Mannan-binding lectin serine protease 1 & -1.1 & 0.0067 \\
\hline P02745 & C1QA & Complement $\mathrm{C} 1 \mathrm{q}$ subcomponent subunit $\mathrm{A}$ & -1.1 & 0.0005 \\
\hline P00488 & F13A1 & Coagulation factor XIII A chain & -1.1 & 0.0003 \\
\hline P00739 & HPR & Haptoglobin-related protein & -1.1 & 0.0002 \\
\hline Q8WWZ8 & OlT3 & Oncoprotein-induced transcript 3 protein & -1.2 & 0.0052 \\
\hline P03951 & F11 & Coagulation factor XI & -1.3 & 0.0001 \\
\hline Q9Y6R7 & FCGBP & IgGFc-binding protein & -1.4 & 0.0333 \\
\hline
\end{tabular}


Table 2 (continued)

\begin{tabular}{|c|c|c|c|c|}
\hline Uniprot ID & Gene name & Protein name & $\log _{2} F C$ & $p$-value \\
\hline Q15485 & FCN2 & Ficolin-2 & -1.5 & $<0.0001$ \\
\hline P06312 & IGKV4-1 & Ig kappa chain V-IV region & -3.0 & $<0.0001$ \\
\hline
\end{tabular}

A $\log _{2}$ FC \pm 1 indicates a twofold increase (+) or decrease (-) in SCLC compared to controls.

SCLC small cell lung cancer, FC fold change

Chronic inflammation is a key promoter of carcinogenesis and its acceleration in cancer patients is linked to disease progression [28]. For SCLC patients, we observed both an upregulation (i.e. CRP, TFRC, ANPEP, SAA1, SAA2, ORM1, and HP) and downregulation (i.e. FCN2) of inflammation markers. Similar findings have previously been described in lung cancer patients [29-35]. Moreover, we also observed a significantly upregulated expression of proteins related to tumorigenesis, metastasis, and cell proliferation (ILK, ITGA6, LGALS3BP, and LRG1) in SCLC patients compared to HCs, and similar findings have also been documented for NSCLC patients [36-39]. Additionally, the two tumor-metastatic markers, ANK1 and GYPA, were also identified as downregulated in SCLC patients. These findings were also confirmed previously in NSCLC patients [40, 41]. Importantly, we observed a ninefold decrease in MV-derived $\alpha$-and $\beta$ subunits of spectrins, indicating that SCLC microvesicles may be involved in cell adhesion, cell spreading, and metastasis. Comparable aberrant decreases of spectrin subunits were also identified in primary tumors and body fluids from patients with NSCLC and other cancer types [40, 42]. The downregulation of the tumor suppressor marker, GSN, detected in our study has also been reported for NSCLC [43]. Another protein involved in tumourigenesis and identified as significantly diminished in SCLC in our study population was CA1. Similarly, decreased CA1 protein expression has been observed in NSCLC patients [44]. However, in contrast, also augmented levels of CA1 in serum have been observed in early stage NSCLC patients and in tumor tissues from SCLC patients $[45,46]$. Furthermore, the downregulated expression of the oncoprotein, OIT3, the immunomodulatory protein, PGLYRP2, and the blood coagulation factor X1 (F11) have shown high diagnostic ability to distinguish between SCLC patients and HCs. Parallel findings have also been recognized for other cancer types [47-49] but not in NSCLC.

In the current SCLC cohort, downregulation of the inflammation marker (IGKV4-1), the tumor aggressivity associated marker (QSOX1), and the tumor suppressor marker (TGF $\beta 1$ ) were observed. Interestingly, these proteins have been reported to be upregulated in NSCLC and other solid tumors [50-53]. Hence, upon validation, we believe that measurements of all three proteins may have potentials in improving SCLC diagnosis.

Additionally, we observed downregulation of blood hemoglobin markers (HBA1, HBB, and HBD) and peroxiredoxins (PRDX1 and PRDX2) in patients with SCLC, which is opposite to the upregulated levels previously observed in lung cancer patients, predominantly in NSCLC patients $[54,55]$, except for PRDX2 which has been reported to be downregulated in NSCLC [56]. Recently, it has been reported that decreased hemoglobin-to-red blood cell distribution width ratio in NSCLC and SCLC patients is associated with poor prognosis, which is suggested to be caused by an increased amount of hypoxic cells, contributing to an aggressive

\footnotetext{
(See figure on next page.)

Fig. 3a Receiver operating characteristic curves and boxplots of protein candidates for the $20 \mathrm{~K}$ samples. Proteins with diagnostic potential found to be upregulated in the SCLC patients were Serum amyloid A-1 protein (SAA1), C-reactive protein (CRP), Transferrin receptor protein 1 (TFRC), Aminopeptidase N (ANPEP), and Galectin-3-binding protein (LGALS3BP), while the proteins upregulated in the control group were Gelsolin (GSN), Transforming growth factor-beta-induced protein ig-h3 (TGFBI), Hemoglobin subunit beta and delta (HBB and HBD), and $\mathrm{N}$-acetylmuramoyl-L-alanine amidase (PGLYRP2). Boxplots show non-logarithmic label-free quantification (LFQ) intensities excluding NaN (missing) values. AUC area under the curve, CI confidence interval, SCLC small cell lung cancer, LFQ label-free quantification. b Receiver operating characteristic curves and boxplots of protein candidates for the $100 \mathrm{~K}$ samples. Proteins with diagnostic potential found to be upregulated in the SCLC patients were Serum amyloid A-1 and A-2 protein (SAA1 and SAA2), Aminopeptidase N (ANPEP), Haptoglobin (HP), and Complement factor H-related protein 4 (CFHR4), and the proteins upregulated in the control group were lg kappa chain V-IV region (IGKV4-1), Ficolin-2 (FCN2), Coagulation factor XI (F11), Coagulation factor XIII A chain (F13A1), and Hemoglobin subunit alpha (HBA1). Boxplots show non-logarithmic label-free quantification (LFQ) intensities and exclude NaN (missing) values. AUC area under the curve, Cl confidence interval, SCLC small cell lung cancer, LFQ label-free quantification
} 

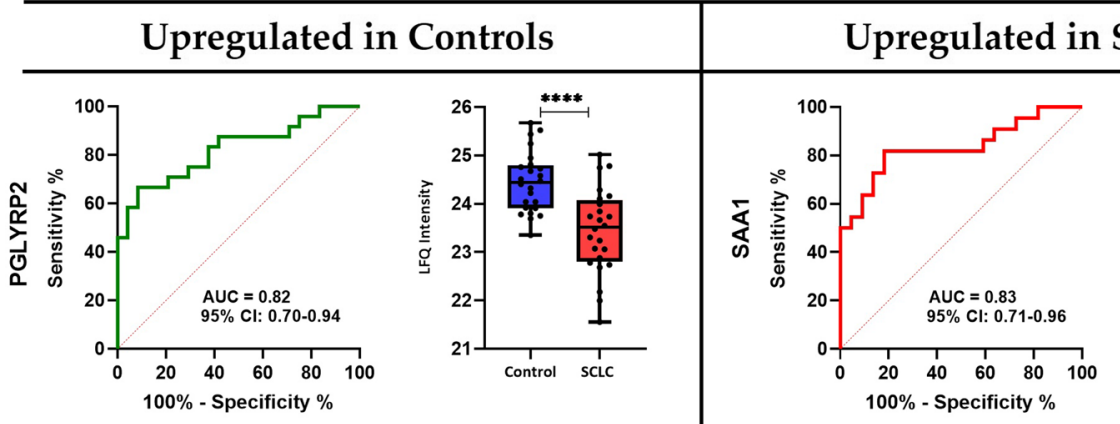

SCLC
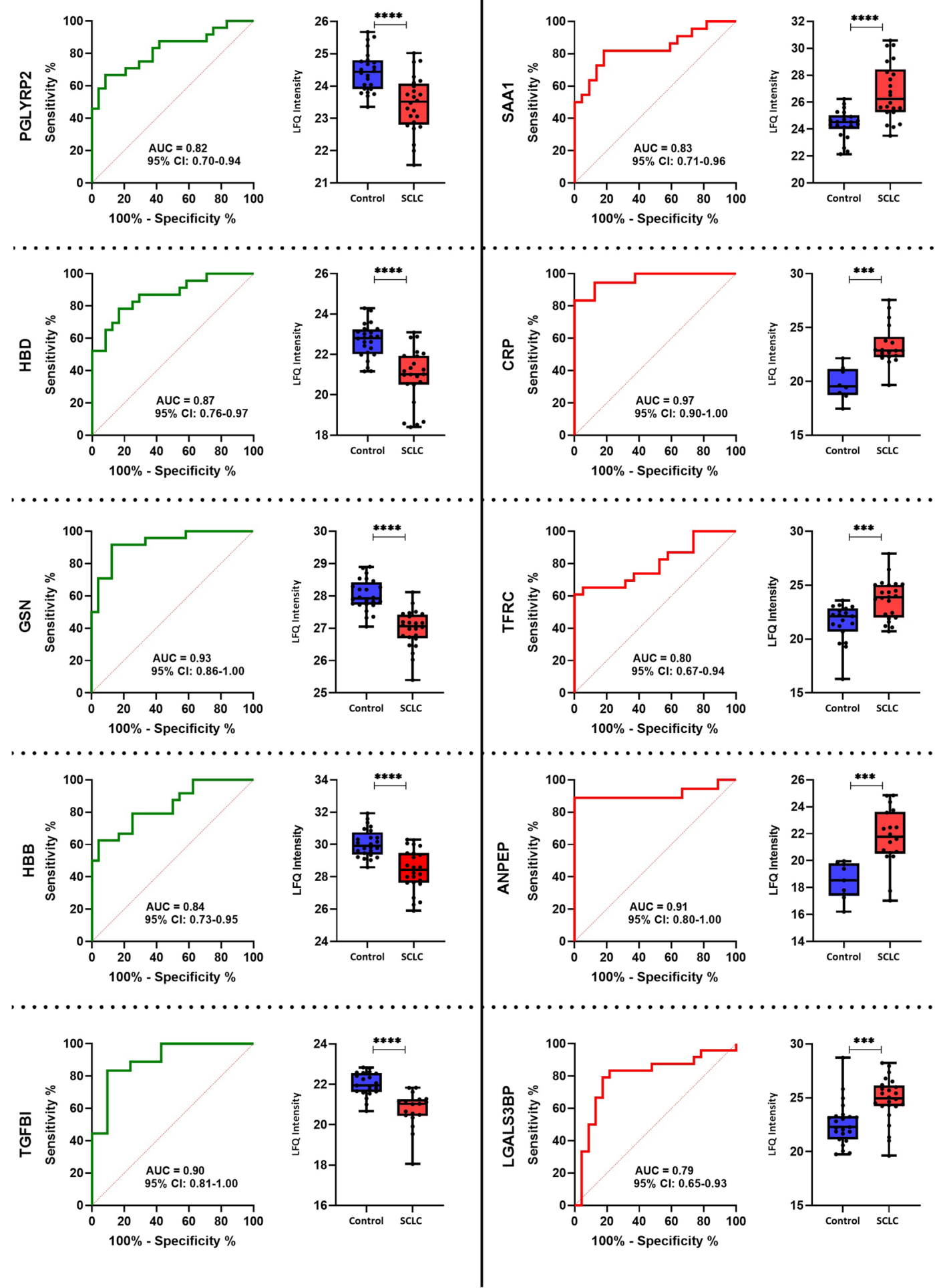

Fig. 3a (See legend on previous page.) 


\section{3b Exosomal proteins with diagnostic potential (100K)}
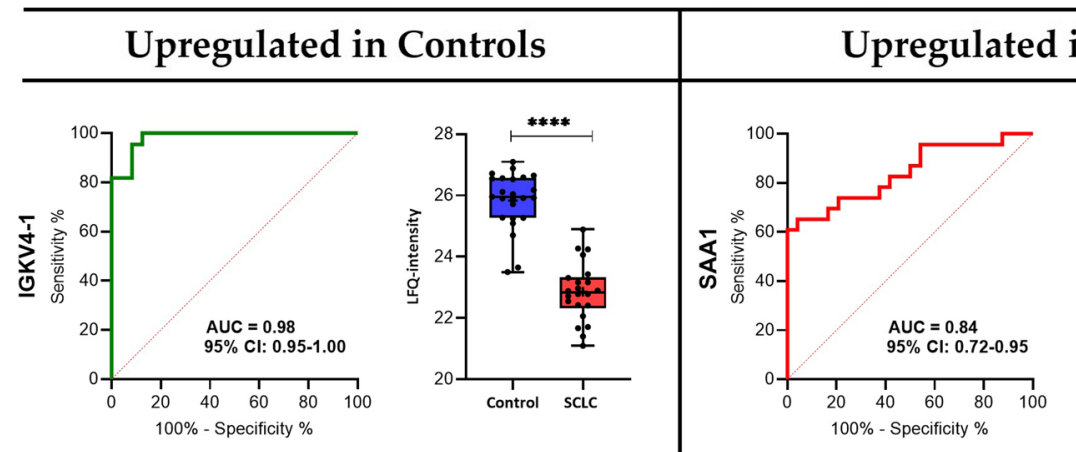

\section{SCLC}
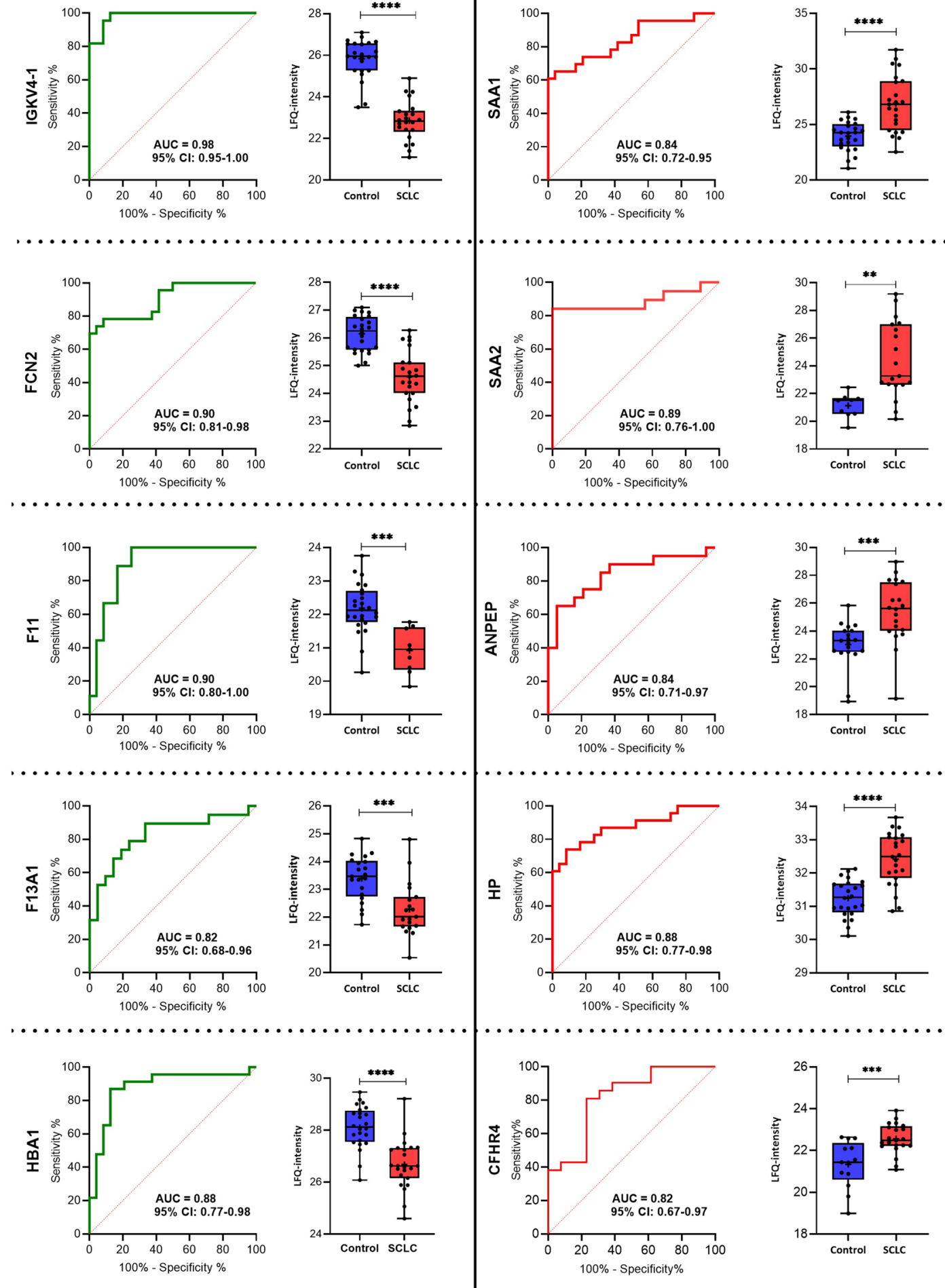

Fig. 3a continued 
Table 3 Potential cancer-related EV biomarkers for SCLC diagnosis based on ROC analysis

\begin{tabular}{|c|c|c|c|c|c|c|}
\hline \multicolumn{7}{|c|}{$20 \mathrm{~K} \mathrm{SCLC} \mid$ control } \\
\hline Protein & AUC & $95 \% \mathrm{Cl}$ & p-value & Sensitivity (\%) & Specificity (\%) & $\log 2 \mathrm{FC}$ \\
\hline ILK & 0.76 & $0.55-0.87$ & 0.0192 & 75 & 59 & 1.0 \\
\hline ORM1 & 0.76 & $0.62-0.89$ & 0.0021 & 79 & 54 & 1.0 \\
\hline GYPA & 0.75 & $0.59-0.90$ & 0.0092 & 77 & 64 & 1.0 \\
\hline QSOX1 & 0.79 & $0.63-0.94$ & 0.0047 & 87 & 63 & -1.1 \\
\hline CA1 & 0.80 & $0.65-0.94$ & 0.0011 & 83 & 74 & -1.2 \\
\hline PRDX2 & 0.73 & $0.58-0.88$ & 0.0083 & 77 & 67 & -1.2 \\
\hline ANK1 & 0.76 & $0.55-0.96$ & 0.0301 & 78 & 70 & -2.6 \\
\hline ITGA6 & 0.74 & $0.59-0.90$ & 0.0084 & 59 & 83 & -2.6 \\
\hline SPTB & 0.75 & $0.54-0.96$ & 0.0419 & 63 & 80 & -2.7 \\
\hline SPTA1 & 0.81 & $0.65-0.98$ & 0.0046 & 82 & 76 & -3.2 \\
\hline \multicolumn{7}{|c|}{$100 \mathrm{~K} \mathrm{SCLC} \mid$ control } \\
\hline Protein & AUC & $95 \% \mathrm{Cl}$ & $p$-value & Sensitivity (\%) & Specificity (\%) & $\log _{2} F C$ \\
\hline APOC2 & 0.81 & $0.65-1.0$ & 0.0140 & 78 & 89 & 2.8 \\
\hline LRG1 & 0.84 & $0.72-0.96$ & 0.0002 & 82 & 75 & 1.2 \\
\hline APOB & 0.86 & $0.76-0.96$ & $<0.0001$ & 83 & 75 & 1.1 \\
\hline PRDX1 & 0.74 & $0.53-0.86$ & 0.0407 & 89 & 50 & -1.0 \\
\hline OIT3 & 0.74 & $0.59-0.83$ & 0.0058 & 76 & 65 & -1.2 \\
\hline
\end{tabular}

A Log $\log _{2} \mathrm{FC} 1$ indicates a twofold increase (+) or decrease (-) in SCLC compared to controls.

$S C L C$ small cell lung cancer, $A U C$ area under the curve, $C l$ confidence interval, $F C$ fold change, $C A 1$ carbonic anhydrase 1, QSOX1 sulfhydryl oxidase 1 , ILK integrinlinked protein kinase, ORM1 alpha-1-acid glycoprotein 1, ANK1 ankyrin-1, GYPA glycophorin-A, ITGA6 integrin alpha-2, PRDX2 peroxiredoxin-2, SPTB spectrin beta chain erythrocytic, SPTA1 Spectrin alpha chain erythrocytic 1, APOC2 Apolipoprotein C-II, LRG1 leucine-rich alpha-2-glycoprotein, APOB apolipoprotein B, PRDX1 peroxiredoxin-1, OIT3 oncoprotein-induced transcript 3 protein

tumor phenotype [57]. This is in agreement with our data, suggesting that oxidative stress may be a driver in or a consequence of SCLC pathogenesis. Furthermore, SCLC patients exhibited increased protein expressions of lipid transport markers (APOB and APOC2), but decreased levels of APOA4 (Additional file 5: Table S4) when compared to HCs. Previously, APOB has been shown to be downregulated in NSCLC patients [58], thus revealing the ability of APOB to discriminate between NSCLC and SCLC. Remarkably, APOC3 protein expression has been previously shown to be significantly lower in SCLC tissues compared to both NSCLC and normal tissue [59]. However, these results may be influenced by the effect of non-fasting patients at time of diagnosis in our study and probable contamination of lipoproteins in the EV fractions. Therefore, further research should be conducted to confirm our findings.

The significant downregulation of coagulation factor XIII A chain (F13A1) and upregulation of the complement factor H-related protein 4 (CFHR4) in SCLC compared to HCs has not yet been identified in other cancers, including lung cancer. In the study we present evidence that these markers could serve as future diagnostic markers in SCLC with an AUC of 0.82 for F13A1 and CFHR4 (95\% CI: $0.69-0.96$ and 95\% CI: 0.67-0.97, respectively).
Cancer patients are generally hypercoagulable, and hence, associated with a high risk of venous thromboembolism [60]. Therefore, the downregulation of F13A1 in SCLC is surprising, but may indicate a novel tumor suppressing role of blood coagulation in SCLC pathogenesis, which is supported by the similar downregulated expression of F11 in SCLC patients in the current study.

CFHR4, a soluble regulator of the complement cascade, is generally known to boost complement activation [61], a process presumed to contribute to tumor growth [62]. The upregulation of CFHR4 observed in SCLC patients may suggest that complement activation plays a role in SCLC pathogenesis. However, previous studies have reported a significant downregulation of membranebound complement regulators (CD46, CD55, and CD59) in SCLC compared to other cancers, including NSCLC [63]. Thus, our finding indicates that soluble CFHR4 may be specifically expressed in SCLC as a positive regulator of complement activation.

The present study holds some limitations regarding small sample size, EV isolation, and methodological aspects of data analyses. Even though the small number of patients may bias the results, we identified several proteins that showed marked differences in their expression levels among SCLC patients versus HCs. The 
reduced patient size and the limited number of patients with early stage disease $(n=1)$ restricts possible correlations between the early and advanced stages. Additional studies including more early stage patients would be ideal in order to answer this problematic. Other confounding factors possibly impacting our results include co-morbidity and cachexia. However, the last mentioned is rarely the case in patients considered suitable for chemotherapy. Regarding methodology, the MS-datasets contain many missing values, which could result in loss of some potentially important comparisons. However, whether the missing values are a result of LFQ-intensities below the detection limit, or whether the protein is simply not expressed in that particular patient, is uncertain. The number of missing values could probably have been reduced if we used another experimental design. In the present study, we have used the data dependent aquisition (DDA) approach. However, in the last couple of decades another principle of analysis, data independent acquisition (DIA), has emerged that possesses some advantages. DIA has a limited number of missing values compared with DDA due to the stochastic sampling of the latter [64] and DIA may have a higher sensitivity although a direct comparison between the methods is still missing [65]. However, one of the major limitations with DIA is the need to generate spectral libraries for data processing [65]. This requires much higher sample amounts than the limited sample amount present for this investigation. Due to this limitation we have therefore used the well established DDA technique and apparently, the two approaches typically quantify a similar number of peptides and proteins in a single shot analysis $[65,66]$. It has been reported by Cox et al. [67] that using the match between runs option in the MaxQuant analysis is another way to reduce the number of missing values. If match between runs were not used, we would probably loss some of the significant protein markers. Therefore, in our study, we used match between runs to allow for the identification of more proteins. The use of EVs as a source of biomarkers should also be noted in this section, as plasma proteins may adhere to EVs and therefore not be cargo in the EVs. However, that may not exclude these proteins as possible diagnostic biomarkers. The stringency of data filtration is subjective and with harsh filtration techniques, the risk of oversight of important markers cannot be excluded. However, without filtrations, the risk of introducing contaminants into the dataset is plausible, leading to the risk of biased results. Moreover, this study has solely compared SCLC patients with HCs. The diagnostic efficiency may be lower when compared to other cancer patients, e.g. regarding inflammatory markers that are generally upregulated in cancer patients. Lastly, for future studies, having focus on glycosylation could improve the identification of biomarkers in SCLC. Thus, since glycosylation may be altered in diseases such as cancer it will be an advantage in future studies to examine the role of glycolysis in SCLC using glycoproteomics.

\section{Conclusions}

To our knowledge, this is the first study to identify single proteins (CFHR4 and F13A1) and a panel of proteins as potential candidates for SCLC diagnosis using an untargeted quantitative proteomic approach. We observed an altered expression of proteins related to inflammation, coagulation, complement activation, hematological dysfunction, lipid metabolism, and hydrogen peroxide catabolism, as opposed to expression patterns observed in NSCLC and other cancers. However, validation studies verifying these proteins as candidate markers in SCLC are warranted.

\section{Abbreviations}

SCLC: Small cell lung cancer; NSCLC: Non-small cell lung cancer; CT: Computed tomography; FNA: Fine-needle aspiration; EVs: Extracellular vesicles; MVs: Microvesicles; MS: Mass spectrometry; TNM: Tumor, lymph node, metastasis; HCs: Healthy controls; LFQ: Label-free quantification; MISEV: Minimal Information for Studies of Extracellular Vesicles; SD: Standard deviations; PCA: Principal component analysis; FC: Fold change; GOBP: Gene ontology biological process; DAVID: The Database for Annotation, Visualization, and Integrated Discovery; PC: Principal components; ES: Enrichment score; ROC: Receiver operating characteristics; AUC: Area under the curve; Cl: Confidence interval.

\section{Supplementary Information}

The online version contains supplementary material available at https://doi. org/10.1186/s12014-021-09339-5.

Additional file 1: Fig. S1. A supplementary Venn diagram was created to illustrate the proteins uniquely up- and downregulated for $20 \mathrm{~K}$ or $100 \mathrm{~K}$, respectively, and those that are commonly expressed. Venn diagram describing differences between MV and exosomal proteins.

Additional file 2: Table S1. Top 100 proteins related to EVs from EV databases ExoCarta and Vesiclepedia.

Additional file 3: Table S2. Protein clusters and gene names.

Additional file 4: Table S3. Functional Enrichment analysis.

Additional file 5: Table S4. Significantly regulated proteins in $20 \mathrm{~K}$ and $100 \mathrm{~K}$ samples.

Additional file 6: Table S5. Potential diagnostic proteins.

\section{Acknowledgements}

The authors are greatly appreciative to Lone Rosborg from the Department of Clinical Immunology at Aalborg University Hospital and Mette Jespersgaard from blood bank at Aalborg University Hospital for their assistance in enrolment and blood sample collection from patients and controls. We would also like to thank the Department of Clinical Immunology at Aalborg University Hospital in Denmark for kindly allowing us the use of their ultracentrifuge and facilities. We appreciate Nasro Ahmed Malin for the introductory assistance with Perseus.

Authors' contributions

The authors contributions to the manuscript are as follows: SP and KPJ contributed to writing of the manuscript. SP, UF, WMS, CHP and SRK conducted 
patient selection and sample collection. SP, KPJ, BH and RGM conducted sample preparation and data analysis. SP conceived the study and participated in the design and SP, KPJ and BH participated in oversight of the MS experiments. All authors read, edited and approved the final manuscript.

\section{Funding}

Not applicable.

\section{Availability of data and materials}

The $20 \mathrm{~K}$ and $100 \mathrm{~K}$ MS raw data for this manuscript has been uploaded in ProteomeXchange Consortium via the PRIDE partner repository with the dataset identifier PXD028944 and PXD028885, respectively.

\section{Declarations}

\section{Ethics approval and consent to participate}

This study was approved by the North Denmark Region Committee on Health Research Ethics (N-20140055), reported to the Danish Data Protection Authority (2018-731-5589) and performed in accordance with the Declaration of Helsinki. All included participants provided written informed consent before enrolment in the study.

\section{Consent for publication}

Not applicable.

\section{Competing interests}

The authors declare no conflicts of interests.

\begin{abstract}
Author details
'Department of Basic Medical Sciences, College of Medicine, QU Health, Qatar University, 2713 Doha, Qatar. ${ }^{2}$ Department of Clinical Medicine, Aalborg University, Aalborg, Denmark. ${ }^{3}$ Department of Biomedicine, Aarhus University, Aarhus, Denmark. ${ }^{4}$ Department of Clinical Biochemistry, Aalborg University Hospital, Aalborg, Denmark. ${ }^{5}$ Department of Health Science and Technology, Aalborg University, Aalborg, Denmark. ${ }^{6}$ Department of Oncology, Aalborg University Hospital, Aalborg, Denmark. ${ }^{7}$ Translational Radiation Biology and Oncology Laboratory, Centre for Cancer Research, Westmead Institute of Medical Research, Westmead 2145, Australia.
\end{abstract}

Received: 6 October 2021 Accepted: 29 December 2021 Published online: 07 January 2022

\section{References}

1. Ferlay J, Colombet M, Soerjomataram I, Dyba T, Randi G, Bettio M, et al. Cancer incidence and mortality patterns in Europe: estimates for 40 countries and 25 major cancers in 2018. Eur J Cancer. 2018;103:356-87.

2. Inamura K. Lung cancer: understanding its molecular pathology and the 2015 WHO classification. Front Oncol. 2017;7:193.

3. Shepherd FA, Crowley J, Van Houtte P, Postmus PE, Carney D, Chansky $\mathrm{K}$, et al. The International Association for the Study of Lung Cancer Lung Cancer Staging Project: proposals regarding the clinical staging of small cell lung cancer in the forthcoming (Seventh) Edition of the tumor, node, metastasis classification for lung cancer. J Thorac Oncol. 2007;2(12):1067-77.

4. Christensen JD, Tong BC. Computed tomography screening for lung cancer: where are we now? N C Med J. 2013;74(5):406-10.

5. Huang M-D, Weng H-H, Hsu S-L, Hsu L-S, Lin W-M, Chen C-W, et al. Accuracy and complications of CT-guided pulmonary core biopsy in small nodules: a single-center experience. Cancer Imaging. 2019;19(1):51.

6. Pezzuto F, Fortarezza F, Lunardi F, Calabrese F. Are there any theranostic biomarkers in small cell lung carcinoma? J Thorac Dis. 2019;11:S102-12.

7. Molina R, Augé JM, Bosch X, Escudero JM, Viñolas N, Marrades R, et al. Usefulness of serum tumor markers, including progastrin-releasing peptide, in patients with lung cancer: correlation with histology. Tumour Biol J Int Soc Oncodevelopmental Biol Med. 2009;30(3):121-9.

8. Molina R, Auge JM, Filella X, Viñolas N, Alicarte J, Domingo JM, et al. Pro-gastrin-releasing peptide (proGRP) in patients with benign and malignant diseases: comparison with CEA, SCC, CYFRA 21-1 and NSE in patients with lung cancer. Anticancer Res. 2005;25(3A):1773-8.

9. Alberro A, Iparraguirre L, Fernandes A, Otaegui D. Extracellular vesicles in blood: sources, effects, and applications. Int J Mol Sci. 2021;22:8163.

10. Mathew M, Zade M, Mezghani N, Patel R, Wang Y, Momen-Heravi F. Extracellular vesicles as biomarkers in cancer immunotherapy. Cancers (Basel). 2020;12(10):2825.

11. Liang B, Peng P, Chen S, Li L, Zhang M, Cao D, et al. Characterization and proteomic analysis of ovarian cancer-derived exosomes. J Proteomics. 2013;80:171-82.

12. Duijvesz D, Burnum-Johnson KE, Gritsenko MA, Hoogland AM, Vredenbregt-van den Berg MS, Willemsen R, et al. Proteomic profiling of exosomes leads to the identification of novel biomarkers for prostate cancer. PLoS ONE. 2013;8(12):e82589-e82589.

13. An T, Qin S, Sun D, Huang Y, Hu Y, Li S, et al. Unique protein profiles of extracellular vesicles as diagnostic biomarkers for early and advanced non-small cell lung cancer. Proteomics. 2019;19(12):1800160.

14. Niu L, Song X, Wang N, Xue L, Song X, Xie L. Tumor-derived exosomal proteins as diagnostic biomarkers in non-small cell lung cancer. Cancer Sci. 2019;110(1):433-42.

15. Goldstraw P, Crowley J, Chansky K, Giroux DJ, Groome PA, Rami-Porta $R$, et al. The IASLC Lung Cancer Staging Project: proposals for the revision of the TNM stage groupings in the forthcoming (seventh) edition of the TNM Classification of malignant tumours. J Thorac Oncol. 2007;2(8):706-14.

16. Cehofski L, Kojima K, Terao N, Kitazawa K, Thineshkumar S, Grauslund J, et al. Aqueous fibronectin correlates with severity of macular edema and visual acuity in patients with branch retinal vein occlusion: a proteome study. Investig Ophthalmol Vis Sci. 2020;61(14):6.

17. Ludvigsen M, Thorlacius-Ussing L, Vorum H, Moyer MP, Stender MT, Thorlacius-Ussing O, et al. Proteomic characterization of colorectal cancer cells versus normal-derived colon mucosa cells: approaching identification of novel diagnostic protein biomarkers in colorectal cancer. Int J Mol Sci. 2020;21(10):3466.

18. Deutsch EW, Bandeira N, Sharma V, Perez-Riverol Y, Carver JJ, Kundu DJ, et al. The ProteomeXchange consortium in 2020: enabling "big data" approaches in proteomics. Nucleic Acids Res. 2020;48(D1):D1145-52.

19. Perez-Rerez Y, Cscordas A, Bai J, Bernal-Llinares M, Hewapathirana S, Kundu DJ, et al. The PRIDE database and related tools and resources in 2019: improving support for quantification data. Nucleic Acids Res. 2019:47(D1):D442-50.

20. Tyanova S, Temu T, Cox J. The MaxQuant computational platform for mass spectrometry-based shotgun proteomics. Nat Protoc. 2016;11(12):2301-19.

21. Oliveros JC. Venny. An interactive tool for comparing lists with Venn's diagrams [Internet]. [cited 2021 Feb 7]. Available from: https://bioinfogp. cnb.csic.es/tools/venny/index.html.

22. Pathan M, Fonseka P, Chitti SV, Kang T, Sanwlani R, Van Deun J, et al. Vesiclepedia 2019: a compendium of RNA, proteins, lipids and metabolites in extracellular vesicles. Nucleic Acids Res. 2019;47(D1):D516-9.

23. Keerthikumar S, Chisanga D, Ariyaratne D, Al Saffar H, Anand S, Zhao $\mathrm{K}$, et al. ExoCarta: a web-based compendium of exosomal cargo. J Mol Biol. 2016:428(4):688-92.

24. Huang DW, Sherman BT, Lempicki RA. Systematic and integrative analysis of large gene lists using DAVID bioinformatics resources. Nat Protoc. 2009;4(1):44-57.

25. Huang DW, Sherman BT, Lempicki RA. Bioinformatics enrichment tools: Paths toward the comprehensive functional analysis of large gene lists. Nucleic Acids Res. 2009;37(1):1-13.

26. Pedersen S, Kristensen AF, Falkmer U, Christiansen G, Kristensen SR. Increased activity of procoagulant factors in patients with small cell lung cancer. PLoS ONE. 2021;16(7):e0253613.

27. Théry C, Witwer KW, Aikawa E, Alcaraz MJ, Anderson JD, Andriantsitohaina $\mathrm{R}$, et al. Minimal information for studies of extracellular vesicles 2018 (MISEV2018): a position statement of the International Society for Extracellular Vesicles and update of the MISEV2014 guidelines. J Extracell Vesicles. 2018;7(1):1535750.

28. Landskron G, De La Fuente M, Thuwajit P, Thuwajit C, Hermoso MA. Chronic inflammation and cytokines in the tumor microenvironment. J Immunol Res. 2014;2014:1-19. 
29. Sung H-J, Ahn J-M, Yoon Y-H, Rhim T-Y, Park C-S, Park J-Y, et al. Identification and validation of SAA as a potential lung cancer biomarker and its involvement in metastatic pathogenesis of lung cancer. J Proteome Res. 2011;10(3):1383-95.

30. Vagulienè N, Žemaitis M, Miliauskas S, Urbonienè D, Brigita SR. Comparison of $C$-reactive protein levels in patients with lung cancer and chronic obstructive pulmonary disease. Medicina (B Aires). 2011;47(8):421.

31. Kang S-M, Sung H-J, Ahn J-M, Park J-Y, Lee S-Y, Park C-S, et al. The Haptoglobin $\beta$ chain as a supportive biomarker for human lung cancers. Mol Biosyst. 2011;7(4):1167-75

32. Whitney JF, Clark JM, Griffin TW, Gautam S, Leslie KO. Transferrin receptor expression in nonsmall cell lung cancer. Histopathol Clin Corr Cancer. 1995;76(1):20-5.

33. Murakami H, Yokoyama A, Kondo K, Nakanishi S, Kohno N, Miyake M. Circulating aminopeptidase N/CD13 is an independent prognostic factor in patients with non-small cell lung cancer. Clin Cancer Res Off J Am Assoc Cancer Res. 2005;11(24 Pt 1):8674-9.

34. Ding Q, Shen Y, Li D, Yang J, Yu J, Yin Z, et al. Ficolin-2 triggers antitumor effect by activating macrophages and CD8+ T cells. Clin Immunol. 2017; 183:145-57

35. Ayyub A, Saleem M, Fatima I, Tariq A, Hashmi N, Musharraf SG. Glycosylated Alpha-1-acid glycoprotein 1 as a potential lung cancer serum biomarker. Int J Biochem Cell Biol. 2016;1(70):68-75.

36. Takanami I. Increased expression of integrin-linked kinase is associated with shorter survival in non-small cell lung cancer. BMC Cancer. 2005;5:1.

37. Shen J, Xu J, Chen B, Ma D, Chen Z, Li JC, et al. Elevated integrin a6 expression is involved in the occurrence and development of lung adenocarcinoma, and predicts a poor prognosis: a study based on immunohistochemical analysis and bioinformatics. J Cancer Res Clin Oncol. 2019;145(7):1681-93.

38. Sun L, Chen L, Sun L, Pan J, Yu L, Han L, et al. Functional screen for secreted proteins by monoclonal antibody library and identification of Mac-2 binding protein (Mac-2BP) as a potential therapeutic target and biomarker for lung cancer*. Mol Cell Proteomics. 2013;12(2):395-406.

39. Li Z, Zeng C, Nong Q, Long F, Liu J, Mu Z, et al. Exosomal leucine-richAlpha2-glycoprotein 1 derived from non-small-cell lung cancer cells promotes angiogenesis via TGF- $\beta$ signal pathway. Mol Ther Oncolytics. 2019;14:313-22.

40. Fahrmann JF, Grapov D, Phinney BS, Stroble C, DeFelice BC, Rom W, et al. Proteomic profiling of lung adenocarcinoma indicates heightened DNA repair, antioxidant mechanisms and identifies LASP1 as a potential negative predictor of survival. Clin Proteomics. 2016;13(1):31.

41. Hernández-Hernández A, Rodríguez M, López-Revuelta A, Sánchez Gallego Jl, Shnyrov V, Llanillo M, et al. Alterations in erythrocyte membrane protein composition in advanced non-small cell lung cancer. Blood Cells Mol Dis. 2006;1 (36):355-63.

42. Yang P, Yang Y, Sun P, Tian Y, Gao F, Wang C, et al. $\beta$ Il spectrin (SPTBN1): biological function and clinical potential in cancer and other diseases. Int J Biol Sci. 2020;17(1):32-49.

43. Dosaka-Akita H, Hommura F, Fujita H, Kinoshita I, Nishi M, Morikawa T, et al. Frequent loss of gelsolin expression in non-small cell lung cancers of heavy smokers. Cancer Res. 1998;58(2).

44. Chiang WL, Chu SC, Yang SS, Li MC, Lai JC, Yang SF, et al. The aberrant expression of cytosolic carbonic anhydrase and its clinical significance in human non-small cell lung cancer. Cancer Lett. 2002;188(1-2):199-205.

45. Bin Wang D, Ke LX, Zhang X, Gang Li Z, Xia LC. Carbonic anhydrase 1 is a promising biomarker for early detection of non-small cell lung cancer. Tumor Biol. 2016;37(1):553-9.

46. Hye-Cheol J, Gwang-II K, Sang-Ho C, Kwang-Hyung L, Jung-Jae K, Jeong-Hee $\mathrm{K}$, et al. Proteomic analysis of human small cell lung cancer tissues: up-regulation of coactosin-like protein-1. J Proteome Res. 2011;10:269-76.

47. Xu ZG, Du JJ, Zhang X, Cheng ZH, Ma ZZ, Xiao HS, et al. A novel liverspecific zona pellucida domain containing protein that is expressed rarely in hepatocellular carcinoma. Hepatology. 2003;38(3):735-44.

48. Yang Z, Feng J, Xiao L, Chen X, Yao Y, Li Y, et al. Tumor-derived peptidoglycan recognition protein 2 predicts survival and antitumor immune responses in hepatocellular carcinoma. Hepatology. 2020;71(5):1626-42.

49. Kyriakou DS, Alexandrakis MG, Passam FH, Foundouli K, Matalliotakis E, Koutroubakis IE, et al. Acquired inhibitors to coagulation factors in patients with gastrointestinal diseases. Eur J Gastroenterol Hepatol. 2002;14(12):1383.

50. Sun L, Zhang Z, Yao Y, Li W-Y, Gu J. Analysis of expression differences of immune genes in non-small cell lung cancer based on TCGA and ImmPort data sets and the application of a prognostic model. Ann Transl Med. 2020;8(8):550.

51. Hmmier A, O'Brien ME, Lynch V, Clynes M, Morgan R, Dowling P. Proteomic analysis of bronchoalveolar lavage fluid (BALF) from lung cancer patients using label-free mass spectrometry. BBA Clin. 2017;7:97-104.

52. Sung HJ, Ahn JM, Yoon YH, Na SS, Choi YJ, Kim Yl, et al. Quiescin sulfhydryl oxidase 1 (QSOX1) secreted by lung cancer cells promotes cancer metastasis. Int J Mol Sci. 2018;19(10):3213.

53. González-Santiago AE, Mendoza-Topete LA, Sánchez-Llamas F, Troyo-Sanromán R, Gurrola-Díaz CM. TGF- $\beta 1$ serum concentration as a complementary diagnostic biomarker of lung cancer: establishment of a cut-point value. J Clin Lab Anal. 2011;25(4):238-43.

54. Song Q, Hu W, Wang P, Yao Y, Zeng H. Identification of serum biomarkers for lung cancer using magnetic bead-based SELDI-TOF-MS. Acta Pharmacol Sin. 2011;32(12):1537-42.

55. Park JH, Kim YS, Lee HL, Shim JY, Lee KS, Oh YJ, et al. Expression of peroxiredoxin and thioredoxin in human lung cancer and paired normal lung. Respirology. 2006;11(3):269-75.

56. Najafi Z, Mohamadnia A, Ahmadi R, Mahmoudi M, Bahrami N, Khosravi A, et al. Proteomic and genomic biomarkers for non-small cell lung cancer: peroxiredoxin, haptoglobin, and alpha-1 antitrypsin. Cancer Med. 2020;9(11):3974-82.

57. Wu F, Yang S, Tang X, Liu W, Chen H, Gao H. Prognostic value of baseline hemoglobin-to-red blood cell distribution width ratio in small cell lung cancer: a retrospective analysis. Thorac cancer. 2020;11(4):888-97.

58. Zabłocka-Słowińska K, Płaczkowska S, Skórska K, Prescha A, Pawełczyk K, Porębska l, et al. Oxidative stress in lung cancer patients is associated with altered serum markers of lipid metabolism. In: Chau D, editor. PLoS One. 2019;14(4):e0215246.

59. Shi J, Yang H, Duan X, Li L, Sun L, Li Q, et al. Apolipoproteins as differentiating and predictive markers for assessing clinical outcomes in patients with small cell lung cancer. Yonsei Med J. 2016;57(3):549-56.

60. Ikushima S, Ono R, Fukuda K, Sakayori M, Awano N, Kondo K. Trousseau's syndrome: cancer-associated thrombosis. Jpn J Clin Oncol. 2016;46(3):204-8.

61. Hebecker M, Józsi M. Factor H-related protein 4 activates complement by serving as a platform for the assembly of alternative pathway C3 convertase via its interaction with C3b protein. J Biol Chem. 2012;287(23):19528-36.

62. Pio R, Corrales L, Lambris JD. The role of complement in tumor growth. In: Advances in experimental medicine and biology. New York: Springer New York LLC. 2014; p. 229-62.

63. Niehans GA, Cherwitz DL, Staley NA, Knapp DJ, Dalmasso AP. Human carcinomas variably express the complement inhibitory proteins CD46 (membrane cofactor protein), CD55 (decay-accelerating factor), and CD59 (protectin). Am J Pathol. 1996;149(1):129-42.

64. Bruderer R, Bernhardt OM, Gandhi T, Miladinović SM, Cheng LY, Messner $S$, et al. Extending the limits of quantitative proteome profiling with data-independent acquisition and application to acetaminophentreated three-dimensional liver microtissues. Mol Cell Proteomics. 2015;14(5):1400-10.

65. Krasny L, Huang PH. Data-independent acquisition mass spectrometry (DIA-MS) for proteomic applications in oncology. Mol Omi. 2021;17(1):29-42

66. Ludwig C, Gillet L, Rosenberger G, Amon S, Collins BC, Aebersold R. Dataindependent acquisition-based SWATH-MS for quantitative proteomics: a tutorial. Mol Syst Biol. 2018;14(8).

67. Cox J, Yu SH, Kyriakidou P. Isobaric matching between runs and novel PSM-level normalization in maxquant strongly improve reporter ionbased quantification. J Proteome Res. 2020;19(10):3945-54.

\section{Publisher's Note}

Springer Nature remains neutral with regard to jurisdictional claims in published maps and institutional affiliations. 